\title{
Detection of Genetically Modified Maize MON810 and NK603 by Multiplex and Real-Time Polymerase Chain Reaction Methods
}

\author{
Hsin-Ying Huang And TzU-Ming PAN*
}

Institute of Microbiology and Biochemistry, National Taiwan University, Taipei, Taiwan 106

\begin{abstract}
In this study, the event-specific primers for insecticide-resistant maize, MON810, and herbicidetolerance maize, NK603, have been designed. Simplex PCR and multiplex PCR detection method have been developed. The detection limit of the multiplex PCR is $0.5 \%$ for MON810 and NK603 in $50 \mathrm{ng}$ of the template for one reaction. Quantitative methods based on real-time quantitative PCR were developed for MON810 and NK603. Plasmid pMulM2 as reference molecules for the detection of MON810 and NK603 was constructed. Quantification range was from 0.5 to $100 \%$ in $100 \mathrm{ng}$ of the DNA template for one reaction. The precision of real-time Q-PCR detection methods, expressed as coefficient of variation for MON810 and NK603 varied from 1.97 to $8.01 \%$ and from 3.45 to $10.94 \%$, respectively. The range agreed with European interlaboratories test results (25\%). According to the results, the methods for quantitative detection of genetically modified maize were acceptable.
\end{abstract}

KEYWORDS: Genetically modified maize; multiplex PCR; real-time PCR; event-specific

\section{INTRODUCTION}

Several lines of genetically modified (GM) crops have been authorized as food and feeds. However, there are still several controversial issues existing, such as biosafety, environment risk and ethical concern. Presently, science cannot dispel the doubts completely. Therefore, detection and labeling of GM-foods are necessary. Polymerase chain reaction (PCR) in its different formats has been broadly applied to genetically modified organisms (GMO) detection/analysis and is now a generally accepted method for regulatory compliance purposes. The estimated global area of transgenic crops has increased from 1.7 million hectares in 1996 to 67.7 million hectares in 2003 (1), although consumer acceptance of GMO is rather low, especially in Europe because consumers are still not convinced of the advantages of GMO. Numerous opinions have been expressed, but the arguments surrounding GMO crops and their processed foods generally focus on two topics: safety and labeling. In light of this, many countries and international organizations have introduced labeling limits. The threshold for the uninternational mixing level of GMO is defined as $1 \%$ in the EU (European Commission (EC) "Novel Food" directive (258/97 EC), Council Regulation (1139/98)) (2), 3\% in Korea, and $5 \%$ in Japan and Taiwan (3).

More recently, real-time PCR procedures for detecting and quantifying the events Maximizer 176 maize and Roundup Ready soybean (RRS) in food was reported by Vaïtiligom et al. (4). However, there are two difficulties of conventional PCR used in GMO analysis: first, different copy numbers of integrated constructs in different GMO events, and second, different GMO events containing identical transgenic construct.

* To whom correspondence should be addressed. Tel.: +886-2-23630231 ext 3813. Fax: +886-2-23627044. E-mail: tmpan@ntu.edu.tw.
For example, the GMO events MON810, MON802, and MON809 also contain the truncated cryIAb gene. Current methods of constructing GMOs lead to random integration of insert DNA into the plant genome, so the integration of the foreign DNA into the genome of a plant is unlikely to occur twice at the same genome locus. The integration border between the construct and the host genome is unique for each particular transformation event (5). A semiquantitative event-specific agarose gel method based on nested PCR for detection of Bt11 DNA has already been published (6), and quantitative eventspecific methods using real-time PCR for detection of RRS (712), MON810 (5, 11), Bt11 (13-14), and Bt176 (4, 12-13) also have already been described. In 2002, Kuribara et al. (16) reported a new method for quantitating the amounts of GMO by using plasmid DNA as reference molecule in place of raw materials whose quality was affected by many factors, such as variety, growing area and year, and the different genotypes of embryos and albumen.

In this paper, we designed event-specific primers for MON810 and NK603 to detect GM maize by multiplex PCR and quantitate the amounts of GM maize by real-time PCR, using plasmid DNAs as reference molecules (RM) in place of raw materials.

\section{MATERIALS AND METHODS}

Materials. Genuine seeds of GM soybean, Roundup Ready Soy (RRS) and GM maize, MON810, NK603, and GA21 were developed and kindly provided by Monsanto Co. (St. Louis, MO). Certified reference material IRMM-410R and IRMM-413 were purchased from Fluka (Buchs SG, Switzerland). A 100-mg sample of above compounds were extracted and purified according to the report published by Lipp et al. (15).

Primers and Probes. Sequences of primers and TaqMan probes listed in Table 1 were designed using the Primer Express (Applied 
Table 1. List of Primers and TaqMan Probes for PCR Systems

\begin{tabular}{|c|c|c|c|c|c|c|}
\hline $\begin{array}{l}\text { PCR } \\
\text { system }\end{array}$ & target & $\begin{array}{l}\text { primer } \\
\text { name }\end{array}$ & sequence $\left(5^{\prime}-3^{\prime}\right)$ & specificity & $\begin{array}{l}\text { amplicon } \\
\text { (bp) }\end{array}$ & $\begin{array}{l}\text { reference/ } \\
\text { gene bank }\end{array}$ \\
\hline A & MON810 maize & $\begin{array}{l}\text { M810mzpF3 } \\
\text { M810mzpR3 } \\
\text { M810p }\end{array}$ & $\begin{array}{l}\text { TCTTGTGCTGATGAAGGTATGTCC } \\
\text { TCGGCAGAGGCATCTTCAA } \\
\text { 5'FAM-TTTGCCATTGCCCAGCTATCTGTCAC-TAMRA } 3^{\prime}\end{array}$ & maize genome/P35S & 223 & AF434709 \\
\hline B & NK603 maize & $\begin{array}{l}\text { Nk603mzpF } \\
\text { Nk603mzpR } \\
\text { Nk603p }\end{array}$ & $\begin{array}{l}\text { CGGCCAGCAAGCCTTGTA } \\
\text { TCCCGACTCTCTTCTCAAGCA } \\
\text { 5'FAM-CCGCGTTAACAAGCTTACTCGAGGTCATTC-TAMRA } 3^{\prime}\end{array}$ & $\begin{array}{l}\text { maize genome/ } \\
\text { rice actin } 1 \text { promoter }\end{array}$ & 113 & AX342368 \\
\hline \multirow[t]{6}{*}{ C } & endogenous maize & $\begin{array}{l}\text { ivr-F } \\
\text { ivr-R } \\
\text { ivr-p }\end{array}$ & $\begin{array}{l}\text { TGGCGGACGACGACTTGT } \\
\text { AAAGTTTGGAGGCTGCCGT } \\
\text { 5'VIC-CGAGCAGACCGCCGTGTACTTCTACC-TAMRA 3 }\end{array}$ & $\begin{array}{l}\text { invertase gene } \\
\text { Exon } 5\end{array}$ & 79 & $\begin{array}{l}\text { Brodmann et al., } \\
2002 \text { (21) U16123 }\end{array}$ \\
\hline & endogenous maize & $\begin{array}{l}\text { Zel } 1-5^{\prime} \\
\text { Zel } 1-3^{\prime}\end{array}$ & $\begin{array}{l}\text { CCTCAGTCGCACATATCTACTATACT } \\
\text { CTAGAATGCAGCACCAACAAA }\end{array}$ & zein gene & 508 & $\begin{array}{l}\text { Matsuoka et al., } \\
\quad 2000 \text { (22) }\end{array}$ \\
\hline & $\begin{array}{l}\text { construction of } \\
\text { pMulM2 }\end{array}$ & Tivr-R & CATCAGCACAAGAAAAGTTTGGA & $\begin{array}{l}\text { tailed the amplicon } \\
A \text { and } B \text { for connection }\end{array}$ & & this study \\
\hline & $\begin{array}{l}\text { construction of } \\
\text { pMulM2 }\end{array}$ & TM810mzpF3 & CTCCAAACTTTTCTTGTGCTGAT & & & this study \\
\hline & $\begin{array}{l}\text { construction of } \\
\text { pMulM2 }\end{array}$ & TM810mzpR3 & GCTGGCCGTCGGCAGAG & $\begin{array}{l}\text { tailed the amplicon } \\
\mathrm{B} \text { and } \mathrm{C} \text { for connection }\end{array}$ & & this study \\
\hline & $\begin{array}{l}\text { construction of } \\
\text { pMulM2 }\end{array}$ & TNK603mzpF & ССTCTGCCGACGGCCAG & & & this study \\
\hline
\end{tabular}

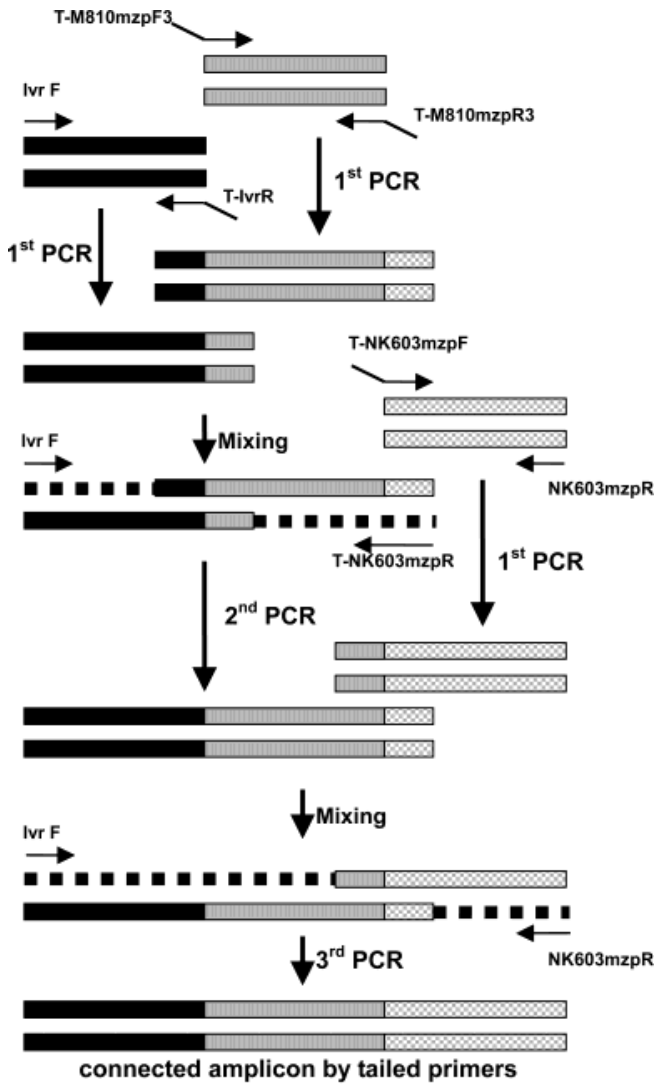

Amplicon A amplified by ivr F/ivr R;
Amplicon B amplified by M810mzpF3/M810mzpR3;
Amplicon C amplified by NK603mzpF/NK603mzpR

Figure 1. Schematic diagrams of hybrid amplicon.

Biosystems, St. Louis, MO) and the Primer Premier 5 (PREMIER Biosoft Int., Palo Alto, CA).

Reference Molecules . To connect the amplicons of PCR systems A-C as reference molecules for MON810 and NK603, we followed the method reported by Kuribara et al. (16) (Figure 1). The intergrated fragment was ligated into pGEM-T-Easy Vector (Promega, Madison, WI) by using TA cloning.
PCR Condition. Multiplex PCR. Conventional PCR was carried out in GeneAmp PCR System 2400 (Perkin-Elmer, Norwalk, CT), PCR Express or PCR Sprint (TheromoHybaid, Ashwalk, Middlesex, UK) thermocycler in a final volume of $25 \mu \mathrm{L}$, containing $200 \mathrm{nM} \mathrm{dNTP}$, $600 \mathrm{nM}$ M810mzpF3/M810mzpR3, $1 \mu \mathrm{M}$ NK603mzpF/NK603mzpR, $600 \mathrm{nM}$ Zel1-5'/Zel1-3', 2.5 units Taq DNA polymerase, $50 \mathrm{ng}$ DNA of samples, and $1 \times$ reaction buffer. Conditions for amplification were as follows: denaturing of DNA at $95{ }^{\circ} \mathrm{C}$ for $5 \mathrm{~min}, 40$ cycles of $30 \mathrm{~s}$ at $95^{\circ} \mathrm{C}, 10 \mathrm{~s}$ at $58{ }^{\circ} \mathrm{C}, 10 \mathrm{~s}$ at $72{ }^{\circ} \mathrm{C}$, and a final extension at $72{ }^{\circ} \mathrm{C}$ for $7 \mathrm{~min}$. Amplification products were electrophoresed in $2 \%$ agarose gels for approximately $30 \mathrm{~min}$ at $100 \mathrm{~V}$ and stained with EtBr for visualization.

Real-Time PCR. End concentrations of real-time PCR components were as follows: $25 \mu \mathrm{L}$ of $2 \times$ TaqMan Universal PCR master mix buffer (Applied Biosystem, St. Louis, MO, including $1 \times$ TaqMan buffer A, $5 \mathrm{mM} \mathrm{MgCl} 2,8 \%$ glycerol, $200 \mu \mathrm{M}$ dNTP (dATP, dCTP, and dGTP), $400 \mu \mathrm{M}$ dUTP, 0.125 units Amperaes uraxil-N-glycosylase (UNG), 0.3 units AmpliTaq Gold DNA polymerase, and $200 \mathrm{nM}$ passive reference dye ROX (6-carboxyrhodamine)), $200 \mathrm{nM}$ TaqMan probe M810p, NK603p, or ivr-VIC, $200 \mathrm{nM}$ primers M810mzpF3/ M810mzpR3, NK603mzpF/NK603mzpR or ivr-F/ivr-R, and $100 \mathrm{ng}$ DNA of samples.

The PCR conditions on ABI PRISM 7700 sequence detection system (Applied Biosystems, St. Louis, MO) were as follows: 1st step, 2 min at $50{ }^{\circ} \mathrm{C}$ and $10 \mathrm{~min}$ at $95^{\circ} \mathrm{C}$; 2nd step, $15 \mathrm{~s}$ at $95^{\circ} \mathrm{C}$ and $1 \mathrm{~min}$ at 60 ${ }^{\circ} \mathrm{C}, 45$ cycles.

\section{RESULTS AND DISCUSSION}

Qualitative Analysis of the GM Maize by Multiplex PCR. Specificity and Sensitivity. The event-specific primers, M810mzpF3/M810mzpR3 and NK603mzpF/NK603mzpR were designed for MON810 and NK603, respectively. By using the genomic DNA from various maize and these specific primers for each r-DNA and endogenous gene, zel, we were able specifically to amplify DNA strands of the expected size by PCR as shown in Figure 2. The expected amplification products by M810mzpF3/M810mzpR3 and NK603mzpF/NK603mzpR were obtained in MON810 and NK603, respectively, and the expected amplification products by Zel1-5'/Zel1-3' were obtained in all maize. Each amplified DNA was confirmed to correspond to each r-DNA or the zel gene by sequencing (Seeing Bioscience Co., Ltd., Taipei, Taiwan).

With three pairs of primers, M810mzpF3/M810mzpR3, NK603mzpF/NK603mzpR, and Zel1-5'/Zel1-3', in one reac- 


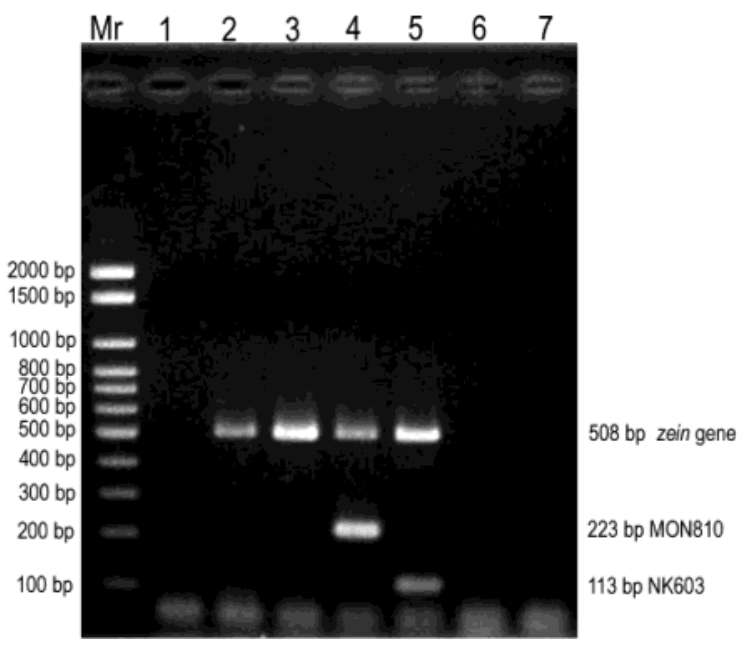

Figure 2. Specificity of multiplex PCR using primer pairs, M810mzpF3/ M810mzpR3, NK603mzpF/NK603mzpR, and Zel1-5'/Zel1-3', designed for MON810, NK603 and zein gene. Mr: 100 bp Bio -100 DNA Ladder. Lanes 1-7: No template control, 50 ng DNA of non-GM maize, GA21, MON810, NK603, non GM soybean, RRS

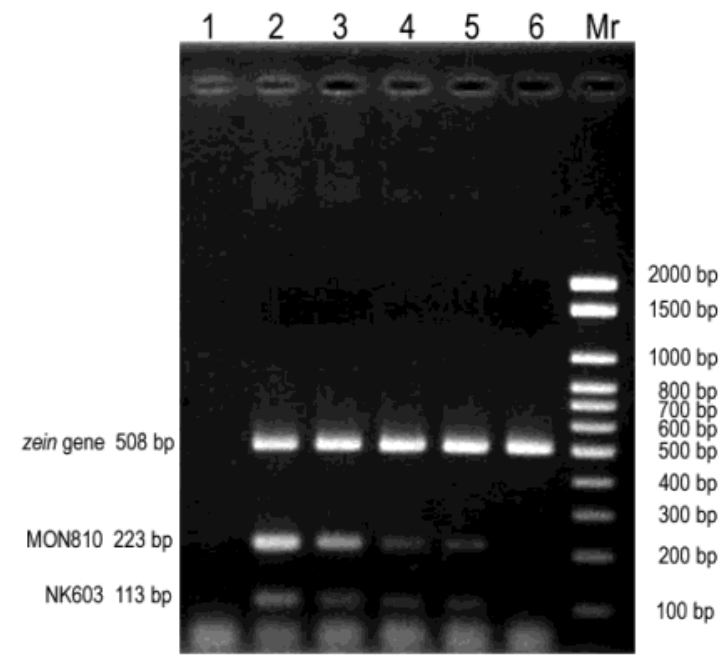

Figure 3. Sensitivity of multiplex PCR using primer pairs, M810mzpF3/ M810mzpR3, NK603mzpF/NK603mzpR and Zel1-5'/Zel1-3', designed for MON810, NK603 and zein gene. Mr: 100 bp Bio -100 DNA Ladder. Lanes 1-6: no template control, 50 ng DNA of $25,5,1,0.5$, and $0.1 \%$ MON810 and NK603.

tion, the interaction between the six primers caused production of the dimers of primers and the decrease of the PCR efficiency. The efficiency of NK603mzpF/NK603mzpR was affected more seriously than the other two, so we increased the concentration of NK603mzpF/NK603mzpR, and decreased the annealing temperature to increase the PCR efficiency of NK603mzpF/ NK603mzpR.

Transgenic maize grain is usually grown with conventional varieties on farms in the USA. Maize samples were mixed into non-GM maize at level of 25, 5, 1, 0.5, and $0.1 \%$ MON810 or NK603. As shown in Figure 3, the detection sensitivity for MON810 and NK603 by multiplex PCR was about $0.5 \%$, approximately 45 copies of genomic DNA of MON810 and NK603. The detection limits meet the labeling requirement of regulations in EU (1\%), Taiwan (5\%), and Japan (5\%).

Quantitative Analysis of the GM Maize by Real-Time PCR. Reference Molecule. The certified reference materials, composed of the powders of GM or non-GM seed, are expensive, and just a few categories could be bought now. We
Table 2. Efficiency of the Real-Time PCR

\begin{tabular}{clccc}
\hline GM line & \multicolumn{1}{c}{ primers } & $\begin{array}{c}\text { PCR efficiency } \\
(\%)\end{array}$ & SD $^{a}$ & $\begin{array}{c}\mathrm{CV}^{b} \\
(\%)\end{array}$ \\
\hline \multirow{2}{*}{ MON810 } & M810mzpF3/M810mzpR3 & 94 & 3 & 3.19 \\
& ivr-F/ivr-R & 93 & 2 & 2.15 \\
NK603 & NK603mzpF/NK603mzpR & 93 & 1 & 1.08 \\
& ivr-F/ivr-R & 93 & 4 & 4.30
\end{tabular}

${ }^{a} \mathrm{SD}$, standard deviation. ${ }^{b} \mathrm{CV}$, coefficient of variation is calculated by dividing standard deviation by mean value and are given in $\%$. Experiments were performed at least three times.

consulted the sequence in EMBL/GenBank, designed the eventspecific primers by the software, Primer Express, and constructed a plasmid, pMulM2, as shown as Figure 1, containing the target sequences of the real-time PCR, as the reference molecule.

PCR Efficiency. In theory, because both strands of DNA template are copied during PCR, there is an exponential increase of the number of copies of the gene. According to the following formulas, if the efficiency of real-time PCR is $100 \%$, the slope of the standard curve is -3.32 .

$$
\begin{gathered}
\mathrm{Ct}_{N}=\text { slope } \times \log \left(2 X_{0}\right)+Y \text {-intercept } \\
\mathrm{Ct}_{N+1}=\text { slope } \times \log \left(X_{0}\right)+Y \text {-intercept } \\
(1)-(2) \\
1=\text { slope } \times \log (1 / 2) \\
\text { slope }=1 / \log (1 / 2)=-3.32
\end{gathered}
$$

$\mathrm{Ct}_{N}$, threshold cycle is $\mathrm{N} ; \mathrm{Ct}_{N+1}$, threshold cycle is $N+1 ; X_{0}$, initial copies

We can calculate the PCR efficiency of the real-time PCR every time by following formula:

$$
\text { PCR efficiency }(\%)=((10 \wedge(\mid \text { slope } \mid-1))-1) \times 100
$$

In this study, the $R^{2}$ of the standard curve in every detection is between 0.99 and 1 , and the PCR efficiency is more than 90\%, calculated the above formula, as shown in Table 2.

Coefficient Value $\left(C_{V}\right)$. According to the previous report (16), the ratios of r-DNA and endogenous sequence in each genuine seed are calculated by formula 1 and defined as coefficient value $\left(C_{\mathrm{V}}\right)$. GMO amounts $(\%)$ are calculated by formula 2 and defined $C_{\mathrm{V}}$ s.

$$
\begin{array}{r}
C_{\mathrm{V}}=\text { [copies of r-DNA sequence in the DNA } \\
\text { extracted from GM seeds]/[copies of endogenous } \\
\text { sequence in the DNA extracted from GM seeds] }
\end{array}
$$

(Formula 1)

GMO amount $(\%)=[$ copies of r-DNA

sequence in the DNA extracted from GM seeds $\times 100] /$

[copies of endogenous sequence in the DNA extracted

$$
\text { from } \left.\mathrm{GM} \text { seeds } \times C_{\mathrm{V}}\right] \quad(\text { Formula } 2)
$$

The $C_{\mathrm{V}} \mathrm{s}$ of MON810 and NK603 event-specific sequences were 0.25 and 0.73 , respectively. The junction between the r-DNA and maize genomic DNA is unique, so the both ideal $C_{\mathrm{V} S}$ of the MON810 and NK603 will be 1 . According to the previous report (16), the differences between experimental and theoretical values might be generated by differences of PCR 
Table 3. Accuracy Statistics for Quantitative Method

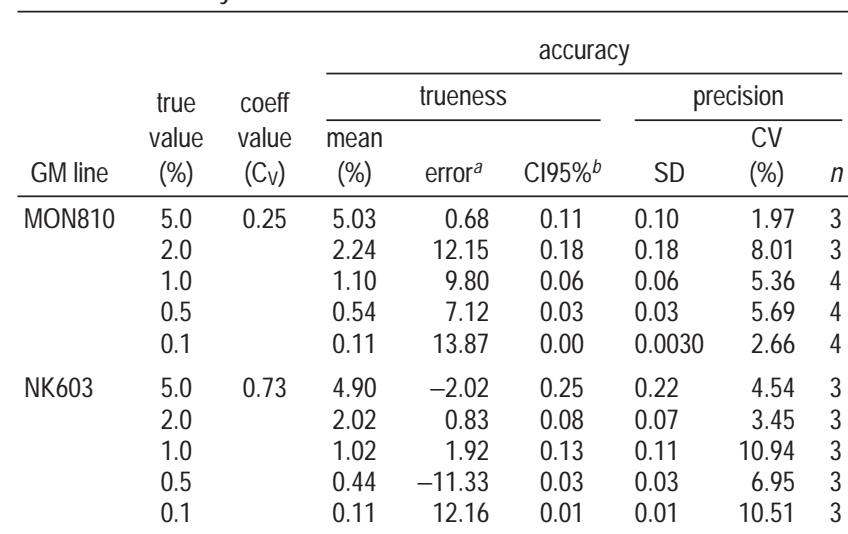

${ }^{a}$ Error, (mean value - true value)/true value $\times 100 .{ }^{b} \mathrm{Cl} 95 \%$, relative $95 \%$ confidence interval.

efficiencies that resulted from the amounts of the nontargeted sequences in the plasmid and genomic DNA.

Range of Quantitation. Five levels of concentration of RMs were set to 20,80,1280, 20480 , and 1310720 copies per reaction for the calibration. According to the genome sizes of maize (18), we considered that the range of copy numbers from 20 to 1310720 was sufficient to quantitate GMO from 0.1 to $100 \%$ in the $100 \mathrm{ng}$ of the template for one reaction. The ranges of quantitation meet the labeling requirement of regulations in EU (1\%), Taiwan (5\%), and Japan (5\%).

Accuracy of Quantitation. Accuracy of the detection method is measured by precision and truness or by repeatability and reproducibility. Precision of quantitation is measured by coefficient of variation $(\mathrm{CV})$, the ratio of standard deviation (SD) and mean value. We detected five levels of MON810 standard materials, 5, 2, 1, 0.5, and $0.1 \%$, and mixed NK603 genuine seeds into non-GM maize at levels as same as those above. The copy numbers of genes of each sample is obtained as mean value of triplicates, at least, compared with the optimal standard curve.

The CVs of detecting the different levels of MON810 and NK603 maize were from 1.97 to $8.01 \%$ and from 3.45 to $10.94 \%$, as shown as Table 3, and the results were similar to the CVs, from 5 to $20 \%$, published by previous papers, which detected the GMO by real-time PCR $(4,19)$, and lower than the CV, 25\%, in report of the co-laboratory study of EU (Report of EU tender No. XXIV/98/A3/001) (20).

Truness (bias) is the difference between experimental mean value and theoretical value. The most difficult problem of detecting the GMO by PCR is the homogenization of samples. The errors of detecting MON810 and NK603 were from 0.68 to $13.87 \%$ and from -11.33 to $12.16 \%$, respectively, as shown in Table 3.

The experimental mean value is directly proportional to theoretical value, as shown in Figure 4, the $R^{2}$ is above 0.99, and the slope is near 1 . The above results revealed that we could detect the GMO content of samples with accuracy by the quantitative detection system in this study.

In this study, we designed "event-specific" primers to detect the GM maize MON810 and NK603. An analytical sample usually includes various lines of GMOs. Using the event-specific primers could avoid the pseudo-positive results caused by other lines of GMOs with the same recombinated-DNA. We also constructed pMulM2 as reference material that could be easily amplified and be cheaper and more stable than the powder of seeds, affected by common agricultural factors. Whether in
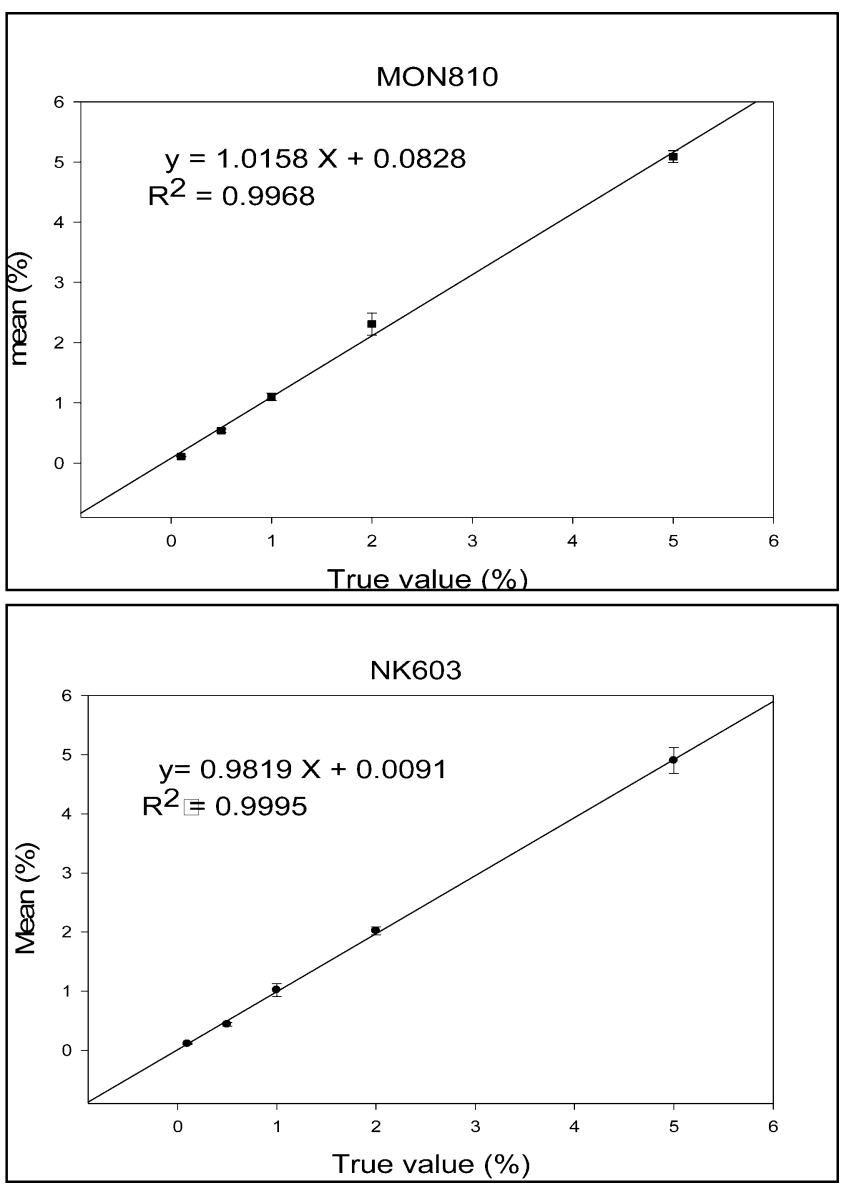

Figure 4. The correlation between the test value and true value of MON810 and NK603 with real-time Q-PCR.

qualitative or quantitative analysis systems, our methods could monitor labeling system sensitively and have allowable levels of accuracy and precision.

\section{LITERATURE CITED}

(1) James, C. Global status of commercialized transgenic crops: ISAAA Briefs. 2003.

(2) Regulation (EC) No. 1139/98 of the European Parliament and of the Council of 26 May 1998 concerning the compulsory indication of the labeling of certain foodstuffs produced from genetically modified organisms of particulars other than those provided for the Directive 79/112/EEC. Off. J. Eur. Communities No. L159/4, 4-7.

(3) http://www.doh.gov.tw.

(4) Vaïtilingom, M.; Pijnenburg, H.; Gendre, F.; Brignon, P. Realtime quantitative PCR detection of genetically modified Maximizer maize and Roundup Ready soybean in some representative foods. J. Agric. Food Chem. 1999, 47, 5261-5266.

(5) Holck, A.; Vaïtilingom, M.; Diderjean, L.; Rudi, K. 5'-Nuclease PCR for quantitative event-specific detection of the genetically modified Mon810 MaisGard maize. Eur. Food Res. Technol. 2002, 214, 449-453.

(6) Zimmermann, A.; Lüthy, J.; Pauli, U. Event specific transgene detection in Bt11 corn by quantitative PCR at the integration site. Lebensm.-Wiss. Technol. 2000, 33, 210-216.

(7) Wurz, A.; Bluth, A.; Zeltz, P.; Pfeifer, P.; Willmund, R. Quantitative analysis of genetically modified organisms (GMO) in processed food by PCR-based methods. Food Control 1999, $10,385-389$.

(8) Berdal, K.; Holst-Jensen, A. Roundup Ready soybean eventspecific real-time quantitative PCR assay and estimation of the practical detection and quantification limits in GMO analyses. Eur. Food Res. Technol. 2001, 213, 432-438. 
(9) Terry, C. F.; Harris, N. Event-specific detection of Roundup Ready soya using two different real time PCR detection chemistries. Eur. Food Res. Technol. 2001, 213, 425-431.

(10) Taverniers, I.; Windels, P.; Depicker, A.; De Loose, M. Use of cloned DNA fragments for event-specific quantification of genetically modified organisms in pure and mixed food products. Eur. Food Res. Technol. 2001, 213, 417-424.

(11) Permingeat, H. R.; Reggiardo, M. I.; and Vallejos, R. H. Detection and quantification of transgenes in grains by multiplex and real-time PCR. J. Agric. Food Chem. 2002, 50, 4431-4436.

(12) Alary, R.; Serin, A.; Maury, D.; Jouira, H. B.; Sirven, J. P.; Gautier, M. F.; Joudrier, P. Comparison of simplex and duplex real-time PCR for the quantification of GMO in maize and soybean. Food Control 2002, 13, 235-244.

(13) Höhne, M.; Santisi, C. R.; Meyer, R. Real-time multiplex PCR: An accurate method for the detection and quantification of 35SCaMV promoter in genetically modified maize-containing food. Eur. Food Res. Technol. 2002, 215, 59-64.

(14) Ronning, S. B.; Vaïtilingom, M.; Berdal, K. G.; Holst-Jensen, A. Event specific real-time quantitative PCR for genetically modified Bt11 maize (Zea mays). Eur. Food Res. Technol. 2003, 216, 347-354.

(15) Lipp, M.; Brodmann, P.; Pietsch, K.; Pauwels, J.; Anklam, E. IUPAC collaborative trial study of a method to detect genetically modified soybeans and maize in dried powder. J. AOAC Int. 1999, 82, 923-928.

(16) Kuribara, H.; Shindo, Y.; Matsuoka, T.; Takubo, K.; Futo, S.; Aoki, N.; Hirao, T.; Akiyama, H.; Goda, Y.; Toyoda, M.; Hino, A. Novel reference molecules for quantitation of genetically modified maize and soybean. J AOAC Int. 2002, 85, 1077-1189.
(17) Chamberlain, J. S.; Gibbs, R. A.; Ranier, J. E.; Nguyen, P. N.; Caskey, C. T. Detection screening of the Duchenne muscular dystrophy locus via multiplex DNA amplification. Nucleic Acids Res. 1988, 16, 11141-11156.

(18) Arumuganathan, K.; Earle, E. D. Nuclear DNA content of some important plant species. Plant Mol. Biol. Report. 1991, 9, $208-$ 218.

(19) Hübner, P.; Waiblinger, H. U.; Piesch, K.; Brodmann, P. D. Validation of PCR method for quantitation of genetically modified plants in food. J. AOAC Int. 2001, 84, 1855-1864.

(20) Report of EU tender No. XXIV/98/A3/001 Development of qualitative as well as quantitative detection methods to identify a genetic modification in soybean and maize productions. http:// europa.eu.int/comm/food/fs/biotech/biotech05_en.pdf.

(21) Brodmann, P. D.; Ilg, E. C.; Berthoud, H.; Herrmann, A. Realtime quantitative polymerase chain reaction methods for four genetically modified maize and maize DNA content in food. $J$. AOAC Int. 2002, 85, 646-653.

(22) Matsuoka, T.; Kuribara, H.; Akiyama, H.; Miura, H.; Goda, Y.; Kusakabe, Y.; Isshiki, K.; Toyoda, M.; Hino, A. A multiplex PCR method of detecting recombinant DNAs from five lines of genetically modified maize. J. Food Hyg. Soc. Jpn. 2000, 42, 24-32.

Received for review January 10, 2004. Revised manuscript received March 17, 2004. Accepted March 22, 2004.

JF049944O 